\title{
Update on entecavir in the management of severe forms of Hepatitis B
}

\author{
This article was published in the following Dove Press journal: \\ Hepatic Medicine: Evidence and Research \\ 14 May 2012 \\ Number of times this article has been viewed
}

\section{Rodolfo Sacco \\ Department of Gastroenterology, Pisa University Hospital, Pisa, Italy}

Correspondence: Rodolfo Sacco Dipartimento di Gastroenterologia-UO Gastroenterologia e Malattie del Ricambio, Azienda Ospedaliero Universitaria Pisana, Ospedale Cisanello Via Paradisa 2, 56124 Pisa, Italy

Tel +39050 9974I I

Fax +390509974I2

Email r.sacco@ao-pisa.toscana.it

\begin{abstract}
Despite the effective management of most cases of hepatitis B virus (HBV) infection, there is still much room for improvement in the treatment of more severe cases of hepatitis B, such as those occurring in patients with decompensated cirrhosis, in transplanted subjects, and in patients with exacerbations of HBV infection. Among the treatments currently approved for the therapy of hepatitis B, entecavir determines a rapid suppression of viral load. This drug is also associated with a high genetic barrier and an overall favorable safety profile. This review provides an overview of recent evidence related to the use of entecavir in the management of the most severe forms of hepatitis B. The results obtained for this drug in real-life clinical practice are also reviewed.
\end{abstract}

Keywords: entecavir, HBV, hepatitis B, chronic hepatitis

\section{Introduction}

Hepatitis B virus (HBV) infection represents a major cause of acute and chronic hepatitis and is associated with a number of long-term complications, such as decompensated cirrhosis and hepatocellular carcinoma (HCC). ${ }^{1,2}$ Several genotypes of HBV exist and HBV genotypes are important predictors of disease progression and treatment outcomes. The burden of HBV is particularly heavy, with a significant impact on the health care system and costs. ${ }^{2}$ In fact, it has been reported that $\approx 5 \%$ of the global population carry HBV infection. ${ }^{1}$ In Europe, the prevalence of HBV ranges between $0.1 \%$ and $7.0 \%$, and increases from west to east and from north to south. in 2009, both the European Association for the Study of the Liver and the American Association for the Study of Liver Diseases issued specific guidelines with the aim of providing guidance on the management of HBV infection in clinical practice. . $^{5,6}$ A detailed review of these recommendations for HBV genotyping and the management of hepatitis B are beyond the scope of this article.

Despite the fact that most cases of HBV infection can be effectively managed, $2,5,6$ substantial improvement is needed in the treatment of more severe cases of hepatitis B, including those occurring in patients with decompensated cirrhosis, in transplanted subjects, and in patients who experience exacerbations of HBV infection. ${ }^{7}$ The recent 2010 Hepatitis B and C Summit Conference in Brussels, Belgium, emphasized the importance of implementing lasting and effective policies to develop more effective management of the severe forms of hepatitis B in clinical practice, with the additional aim of limiting the progression of hepatitis to HCC. ${ }^{7}$

At present, several pharmacological treatments are available for the treatment of chronic hepatitis: interferon- $\alpha 2 \mathrm{a}$ (IFN- $\alpha 2 \mathrm{a}$ ) - marketed in its PEGylated form - and 
six nucleos(t)ide analogs. These include two L-nucleoside analogs (lamivudine and telbivudine), a deoxyguanosine analog (entecavir), and two acyclic nulcleotide phosphonates (tenofovir disoproxil fumarate and adefovir dipivoxil). ${ }^{2}$

Among these drugs, entecavir is an oral nucleoside analog that effectively inhibits $\mathrm{HBV}$ polymerase, resulting in a rapid suppression of viral load in HBV-infected patients. ${ }^{8}$ Given the low rate of resistance and low incidence of complications associated with this drug, current guidelines consider entecavir, together with tenofovir, to be among the preferred first-line treatments for HBV infection. ${ }^{5,6,9}$ Despite the increasing use of entecavir in the treatment of HBV infection, evidence on the efficacy and tolerability of this drug in the most severe forms of hepatitis B is still scant; in addition, data on the effectiveness of entecavir in real-life clinical practice should be reviewed.

This review will provide an overview of the most recent evidence related to the use of entecavir in the management of the most severe forms of hepatitis B. The results obtained from real-life clinical practice are also considered.

\section{Methods}

Studies included in this review were retrieved from the MEDLINE ${ }^{\circledR}$ database using the search terms "entecavir" and "HBV" or "hepatitis B." Papers were selected for inclusion in the present study according to their relevance to the topic. The author also browsed the reference list of each article to identify other relevant papers and provided other sources of evidence from his own personal collection of literature. Relevant websites were considered as a source of evidence. The research was last updated on September 24, 2011.

\section{Pharmacology of entecavir}

Entecavir belongs to the nucleos(t)ide analogs, a class of oral agents with the ability to target the synthesis of DNA and the activity of HBV polymerase, thus inhibiting the replication of HBV (Figure 1). ${ }^{8,10}$

Following administration, the monohydrate form of entecavir undergoes intracellular phosphorylation and is activated to its triphosphate form. ${ }^{11}$ Entecavir effectively inhibits HBV polymerase by competing with deoxyguanosine triphosphate, a molecule necessary for the synthesis of HBV DNA. This inhibition blocks a number of biochemical steps involved in the production of HBV DNA, including base priming, reverse transcription of the negative strand, and synthesis of the positive strand. ${ }^{12}$

Some in vitro studies have revealed that entecavir presents a greater potency (defined as $\mathrm{IC}_{50}$ ) against $\mathrm{HBV}$ than lamivudine or adefovir. ${ }^{13,14}$ In addition, entecavir has demonstrated activity against HBV strains resistant to lamivudine. . $^{13,14}$

Studies of viral kinetics reported a rapid decline in serum HBV DNA levels in patients with chronic HBV infection, following the administration of entecavir. ${ }^{15,16}$ In particular, the decline in HBV DNA reported with entecavir was significantly greater than that observed in patients receiving adefovir in a 48-week randomized clinical trial. ${ }^{16}$ The results of these studies allowed the estimation of the half-life of circulating HBV in patients undergoing entecavir therapy: approximately 14-16 hours versus the 30 hours reported with adefovir treatment. ${ }^{8,15,16}$ Notably, the reduction - and, ultimately, the clearance of serum HBV DNA - is currently considered the primary goal of anti-HBV therapy, as this may reduce the risk of progressive liver disease and the development of resistance to antiviral drugs. ${ }^{8}$

\section{Entecavir in patients with severe forms of hepatitis B Entecavir in patients with decompensated cirrhosis}

Hepatic decompensation represents a major clinical complication in $\mathrm{HBV}$-infected patients; in fact, the reported 5 -year survival rate in subjects with chronic hepatitis B and decompensated cirrhosis ranges from $14 \%$ to $35 \%$ versus $80 \%$ to $86 \%$ reported in patients with compensated cirrhosis. ${ }^{5}$ In particular, the efficacy of interferon- $\alpha$ treatment in this population has been questioned in recent guidelines. ${ }^{6}$ Therefore, the early initiation of nucleos $(\mathrm{t})$ ide analogs is currently recommended in patients with decompensated cirrhosis. ${ }^{5,6}$ Among currently available therapeutic options, lamivudine is associated with high resistance rates. ${ }^{17,18}$ Adefovir presents a suboptimal potency and the potential for renal toxicity - this adverse event is particularly relevant in patients with decompensated cirrhosis, who carry a higher risk of kidney dysfunction. ${ }^{19,20}$ Therefore, entecavir could be considered a promising therapeutic alternative for this population. ${ }^{5}$

Liaw et al have recently published the results of a randomized, open-label comparative study of entecavir versus adefovir therapy in $\mathrm{HBV}$-infected patients with decompensated cirrhosis (Child-Turcotte-Pugh score $\geq 7$ ). ${ }^{21}$ In total, 191 adult subjects (positive or negative for $\mathrm{HBeAg}$ and either experienced or naïve for treatment with nucleos(t)ide analogs) were randomized either to entecavir (1 $\mathrm{mg})$ or adefovir $(10 \mathrm{mg})$ daily for up to 96 weeks. 


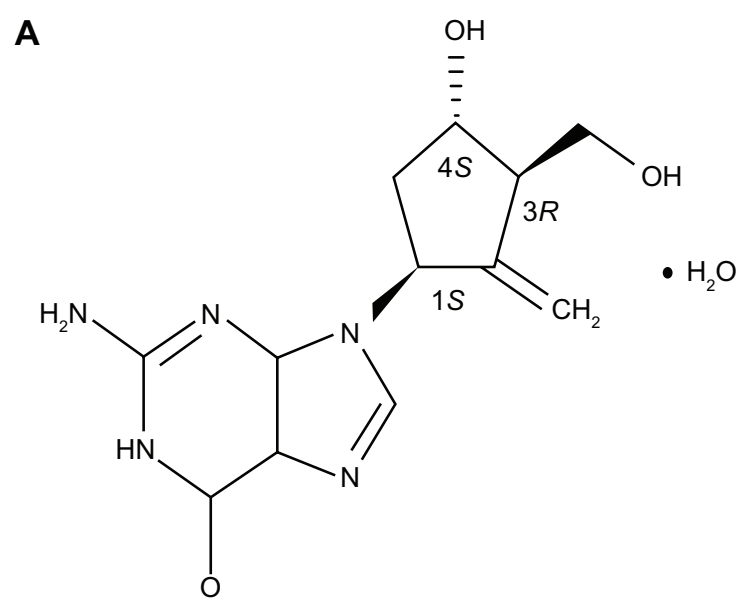

B

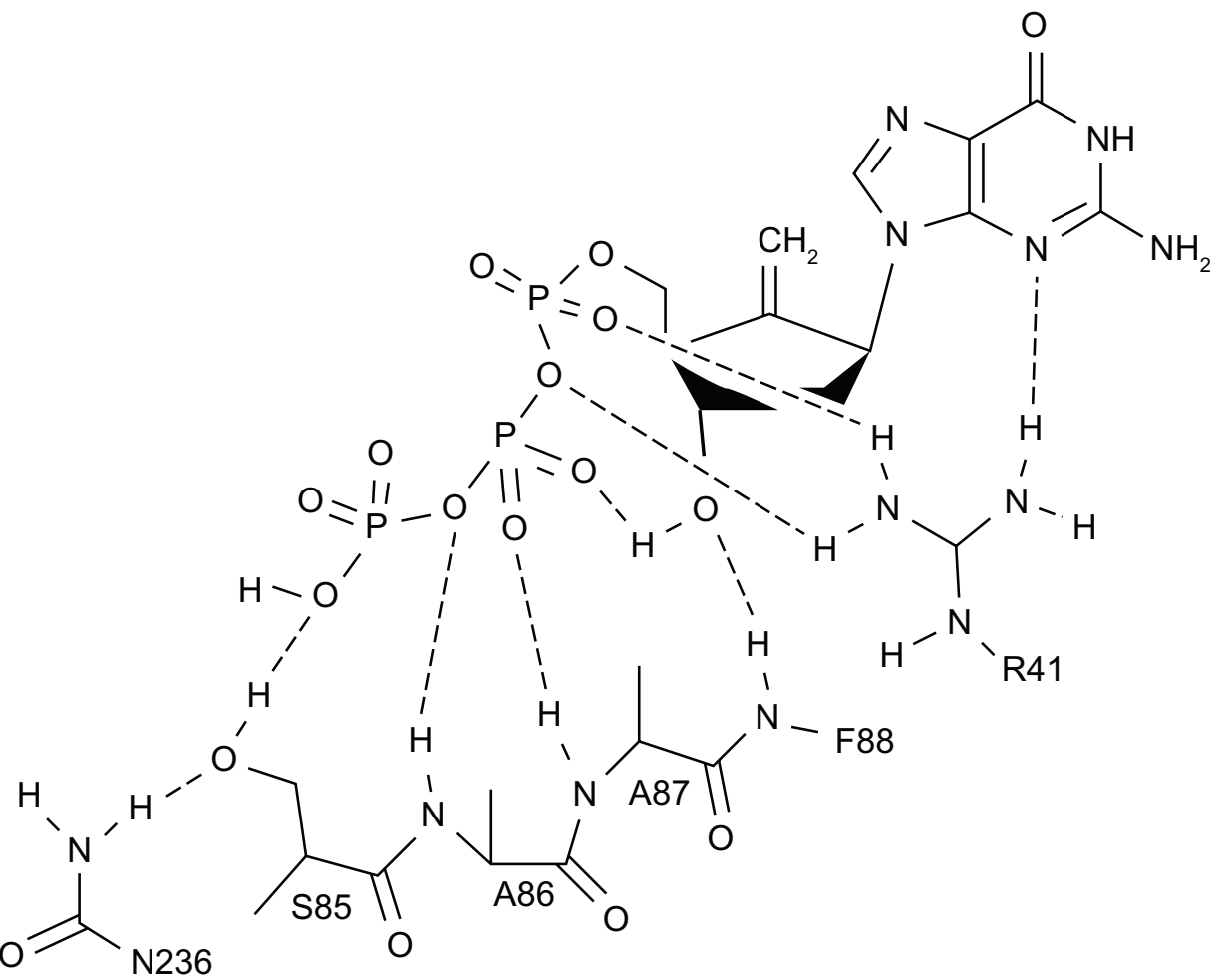

Figure I Chemical structure of entecavir (A) and interaction with hepatitis B virus polymerase (B).

Entecavir was superior to adefovir for the primary efficacy endpoint, ie, the mean reduction in serum HBV DNA at week 24, adjusted for baseline HBV DNA and lamivudine resistance status (treatment difference $1.74 \log _{(10)}$ copies $/ \mathrm{mL}$ [95\% confidence interval $(\mathrm{CI})-2.30$ to -1.18 ]; $P<0.0001)$. In addition, the administration of entecavir determined a greater reduction from baseline in HBV DNA at all time points, and resulted in a higher proportion of subjects who achieved HBV DNA $<300$ copies/mL at weeks 24 (entecavir 49\%; adefovir $16 \% ; P<0.0001$ ) and 48 (entecavir $57 \%$; adefovir $20 \% ; P<0.0001 ;$ Figure 2). Cumulative HCC rates were $12 \%$ for entecavir and $20 \%$ for adefovir, while cumulative death rates were $23 \%$ for entecavir and $33 \%$ for adefovir The safety profile was similar in the two treatment groups; no severe adverse events that may have otherwise been expected in the decompensated population - such as hepatic flares, lactic acidosis, and renal failure - occurred at a higher frequency than expected, according to these patients' previous clinical experiences. The reliable safety profile of entecavir in patients with hepatitis B and decompensated cirrhosis reported in this study is consistent with the results of another Phase II double-blind randomized clinical trial published by the same group. ${ }^{22}$ Taken together, these findings suggest that entecavir may be effective and well 


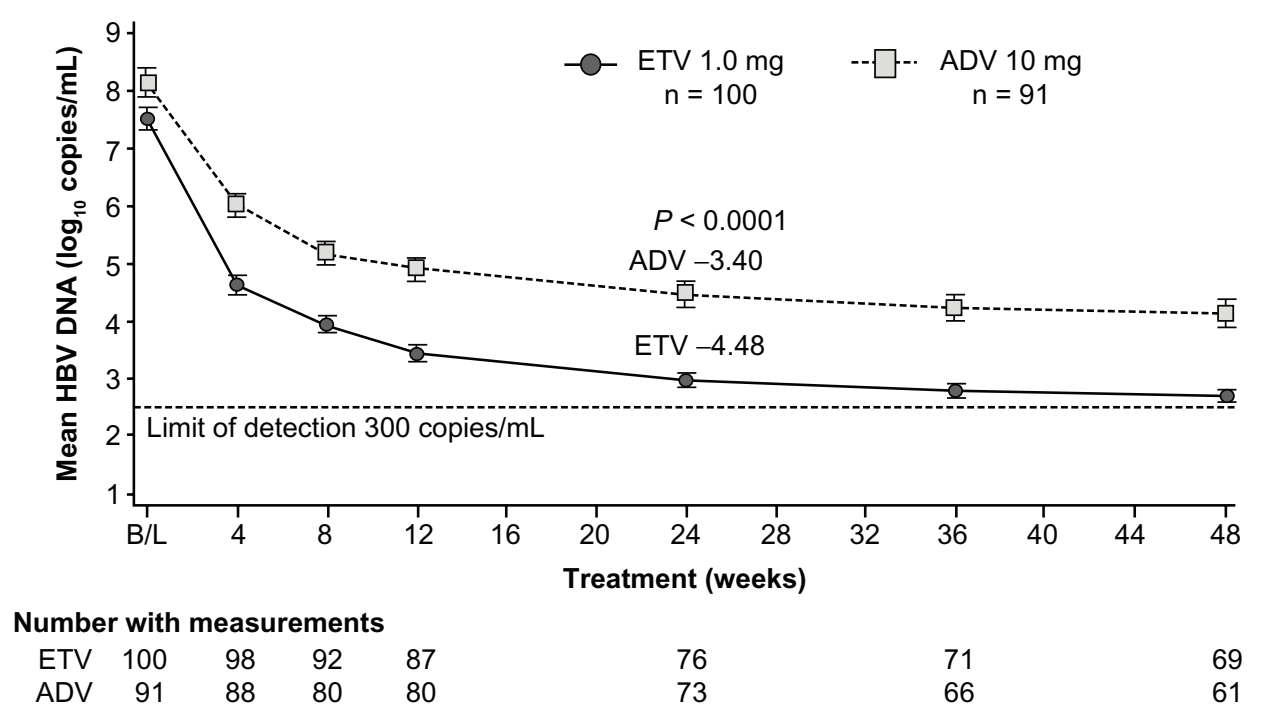

Figure 2 Mean hepatitis B virus DNA change from baseline by polymerase chain reaction through week 48 , in a study comparing entecavir with adefovir in patients with decompensated cirrhosis.

Note: Reproduced from Liaw YF, Raptopoulou-Gigi M, Cheinquer H, et al. Efficacy and safety of entecavir versus adefovir in chronic hepatitis B patients with hepatic decompensation: a randomized, open label study. Hepatology. 20II;54(I):91-100.21

tolerated in patients with chronic hepatitis B who present hepatic decompensation.

\section{Entecavir in patients with exacerbations of HBV infection}

The yearly rate of acute exacerbations in hepatitis $\mathrm{B}$ patients is $10 \%-30 \% .^{23}$ Acute exacerbations have a great clinical relevance, since they may lead to severe or potentially life-threatening consequences - in particular, when accompanied by jaundice and coagulopathy. ${ }^{24,25}$ Despite its efficacy in the treatment of HBV infection, monotherapy with lamivudine does not guarantee significant protection against the rapid progression of severe exacerbations of hepatitis B to hepatic failure. ${ }^{25}$

To our knowledge, the efficacy of entecavir in this therapeutic context has been addressed in two reports. Matsumoto et al described two cases of severe exacerbations of chronic hepatitis B with jaundice and coagulopathy, which were successfully treated with a combination of entecavir (0.5 mg/day) and prednisolone (30 or $50 \mathrm{mg} /$ day). ${ }^{25} \mathrm{In}$ both cases, the patients reported a rapid reduction in serum HBV DNA levels and a clearance of viral load was reached after 12-15 weeks of treatment. After the clearance of viral infection, the corticosteroid was stopped, while entecavir treatment was continued. This benefit was sustained for 1 year from the time that this therapeutic strategy was initiated. The authors concluded that the combination of entecavir and prednisolone may improve the prognosis in severe exacerbations of chronic hepatitis B; however, they pointed out that larger studies are necessary to confirm these findings.

According to the results of this preliminary report, a larger observational study evaluated 153 patients with hepatitis B and severe exacerbations of disease, who were treated either with entecavir $(n=36)$ or lamivudine $(n=117) .{ }^{26}$ By week 48 , seven $(19 \%)$ patients in the entecavir group and five (4\%) patients in the lamivudine group had died (adjusted hazard ratio [HR] 5.1, 95\% CI 1.5-17.2; $P=0.010$ ). In addition, a higher liver-related mortality rate was reported in the entecavir group (adjusted HR 4.0, 95\% CI 1.0-15.7; $P=0.044$ ). What is more, despite a lower prevalence of cirrhosis, more patients on entecavir developed prolonged jaundice, hepatic encephalopathy, or ascites. However, the administration of entecavir resulted in more rapid and complete viral suppression when compared with lamivudine treatment: $71 \%$ of patients treated with entecavir achieved undetectable HBV DNA at week 48 , compared with $40 \%$ in the lamivudine group $(P=0.007)$. These results could suggest that entecavir treatment might be associated with increased short-term mortality, relative to lamivudine, in patients with severe acute exacerbations of chronic hepatitis B; however, at the same time, entecavir could allow for the achievement of a greater virological response over the long-term. Further evidence is necessary to better elucidate the potential role and the optimal therapeutic schemes of entecavir administration for the treatment of hepatitis B patients who experience severe exacerbations of disease. 


\section{Entecavir in patients with fulminant hepatic failure}

The use of entecavir in patients with fulminant hepatic failure, whose prognosis is extremely poor, is still controversial. An anecdotal report has described the case of an 82-year-old asymptomatic HBV carrier who died from fulminant hepatic failure without proximate cause. ${ }^{27}$ The patient was treated with entecavir and corticosteroids and the autopsy revealed a submassive hepatic necrosis with faint regeneration.

Conversely, successful salvage therapy with entecavir has been reported in a patient with decompensated cirrhosis, who experienced virological breakthrough and hepatic failure after withdrawal of lamivudine therapy. ${ }^{28}$ The authors of that case report, which was published within a more complete meta-analysis on the treatment of HBV-associated hepatic failure, supported the potential use of entecavir in this therapeutic context but stressed that additional evidence is required to reach more definite conclusions. ${ }^{28}$

\section{Entecavir in patients with liver transplants}

Liver transplantation currently represents the only effective treatment for HBV-related end-stage liver disease. ${ }^{29}$ The extended use of hepatitis B immunoglobulin (HBIG) has markedly reduced the rate of $\mathrm{HBV}$ recurrence in transplanted patients; in addition, the combination of HBIG and lamivudine has resulted in a further reduction of $\mathrm{HBV}$ recurrence, when compared with HBIG alone. ${ }^{30}$ However, lamivudine is associated with a high rate of resistance in liver-transplanted patients - up to $50 \%$ after 3 years of therapy. ${ }^{31}$ Therefore, an alternative therapeutic option that is associated with a lower rate of resistance is required to limit the incidences of recurrence of hepatitis B after liver transplantation. ${ }^{29}$

$\mathrm{Xi}$ et al reported the results of an observational study (3-year follow-up period) that was conducted on 120 patients who underwent liver transplantations. ${ }^{29}$ Thirty of these received entecavir $(0.5 \mathrm{mg} /$ day $)$ and 90 were treated with lamivudine (100 mg/day); all patients received long-term HBIG at a low dosage. Treatment with entecavir was associated with a significantly lower rate of recurrence of hepatitis $\mathrm{B}$, when compared with lamivudine therapy $(P<0.05$; Table 1); one patient died from liver failure due to $\mathrm{HBV}$ reinfection in the lamivudine group. In addition, patients on entecavir achieved undetectable hepatitis $B$ surface antigen (HBsAg) earlier than those treated with lamivudine, while the survival rate was similar in the two groups (Table 1). No adverse events related to entecavir
Table I Main clinical outcomes in liver-transplanted patients treated with either entecavir $(n=30)$ or lamivudine $(n=90)$, in combination with hepatitis $B$ immunoglobulin for the prevention of hepatitis $B$ virus recurrence

\begin{tabular}{lll}
\hline & Entecavir & Lamivudine \\
\hline Recurrence rate (\%) & 0 & $11 . I^{*}$ \\
Time to undetectable & $3[1-7]$ & $5[1-2 I]^{+}$ \\
HBsAg (days, median) [range] & & \\
Survival rate at 30 months (\%) & 81 & 81 \\
\hline
\end{tabular}

Notes: $* P=0.049$ versus entecavir; ${ }^{+} P=0.003$ versus entecavir. Data from $\mathrm{Xi} Z F$, Xia $Q$, Zhang J], et al. The role of entecavir in preventing hepatitis $B$ recurrence after liver transplantation. J Dig Dis. 2009;10(4):321-327.29

Abbreviation: $\mathrm{HBsAg}$, hepatitis $B$ surface antigen.

were reported. According to the authors, this study suggested that entecavir, combined with low dosages of $\mathrm{HBIG}$, might be an effective and well-tolerated option for the prevention of the recurrence of hepatitis B in patients who undergo liver transplants; however, its long-term effects are still under investigation.

These results are in line with those reported in a very recent study by Fung et al, which was conducted on 80 patients who received a liver transplant for hepatitis B-related disease and entecavir monotherapy ( $0.5 \mathrm{mg} /$ day $)$ as prophylaxis. ${ }^{32}$ The median follow-up was 26 months. None of the patients received HBIG. At the time of transplant, only 21 patients $(26 \%)$ presented undetectable levels of HBV DNA. Despite this, the cumulative rate of $\mathrm{HBsAg}$ loss was $86 \%$ after 1 year and $91 \%$ after 2 years. In total, 18 patients $(22.5 \%)$ were HBsAg positive at the time of their last examination; among these, 17 had undetectable levels of HBV DNA and the remaining patient presented a very low level of HBV DNA (217 copies/mL). Notably, no evidence of mutations at sites that confer resistance to entecavir was reported in HBsAg patients. These results seem to suggest that an HBIG-free regimen of entecavir monotherapy can effectively prevent the recurrence of hepatitis B after liver transplantation.

\section{Entecavir in patients with Crohn's disease}

Recent data have supported the use of entecavir in immunocompromised patients. ${ }^{33}$ In fact, the prevalence of HBV infection is increased in patients with autoimmune conditions; in particular, in those with Crohn's disease due to their increased requirement for high-risk procedures like surgery and endoscopy. ${ }^{34}$ In addition, immunosuppressive drugs used to treat Crohn's disease may alter the balance between viral replication and host immune response, potentially leading to hepatic flare. Our group has described - for the first time to 
our knowledge - the successful management of two cases of hepatic flare attributed to the treatment of acute Crohn's disease with systemic corticosteroids and/or azathioprine. ${ }^{34}$ Both patients had impaired hepatic function and one had experienced jaundice and liver decompensation with ascites. Treatment with entecavir $(0.5 \mathrm{mg}$ /day) determined a reduction in both HBV DNA and hepatic enzyme levels within 4-7 days. Both patients were discharged 2 weeks after admission and HBV-DNA levels became negative after 1 and 5 months, respectively. No adverse events were reported.

\section{Efficacy and safety of entecavir in real-life clinical practice}

Randomized controlled trials (RCTs) are considered the "gold standard" in the hierarchy of research designs, in terms of assessing and critically evaluating the efficacy and safety of a given intervention. However, the results of RCTs might sometimes have limited applicability to patients in real-life clinical settings. ${ }^{35}$ In particular, the analysis of large health care databases can expand upon outcomes of RCTs, because of the inclusion of larger and unselected patient populations who present different comorbidities and are observed for longer follow-up periods. ${ }^{35}$ In addition, well-designed observational studies may allow for the identification of clinically important differences among therapeutic options and provide long-term data on effectiveness and tolerability. ${ }^{35}$
The accurate analysis of data collected in databases and those retrieved from observational studies gains even more relevance in the study of liver disease, a setting in which the design and the conducting of well-organized clinical trials are particularly challenging. ${ }^{36,37}$

A number of real-life clinical practice studies have assessed the efficacy of entecavir in patients with chronic hepatitis $B$. We report here the key results of some particularly relevant experiences.

Buti et al have retrospectively analyzed data from 190 nucleos $(\mathrm{t})$ ide-naïve patients with chronic hepatitis $\mathrm{B}$, who were treated with entecavir monotherapy $(0.5 \mathrm{mg} /$ day $)$ in 25 Spanish centers (the ORIENTE study). ${ }^{38}$ At follow-up at 48 -weeks, over $80 \%$ of patients on entecavir presented undetectable viral load; $61.1 \%$ of HBsAg-positive patients reached this clinical goal (Figure 3). ${ }^{38}$ No cases of resistance or discontinuation of entecavir for the development of adverse events were observed.

In another analysis from the European VIRGIL surveillance group, 161 chronic hepatitis B patients who were either naïve or experienced for treatment with nucleos(t)ide analogs and treated with entecavir monotherapy - were investigated to assess the incidence of virological response. ${ }^{39}$ Over a median follow-up period of 11 months, 82 (79\%) of 104 nucleos(t)ide analognaïve patients achieved a virological response; no patient

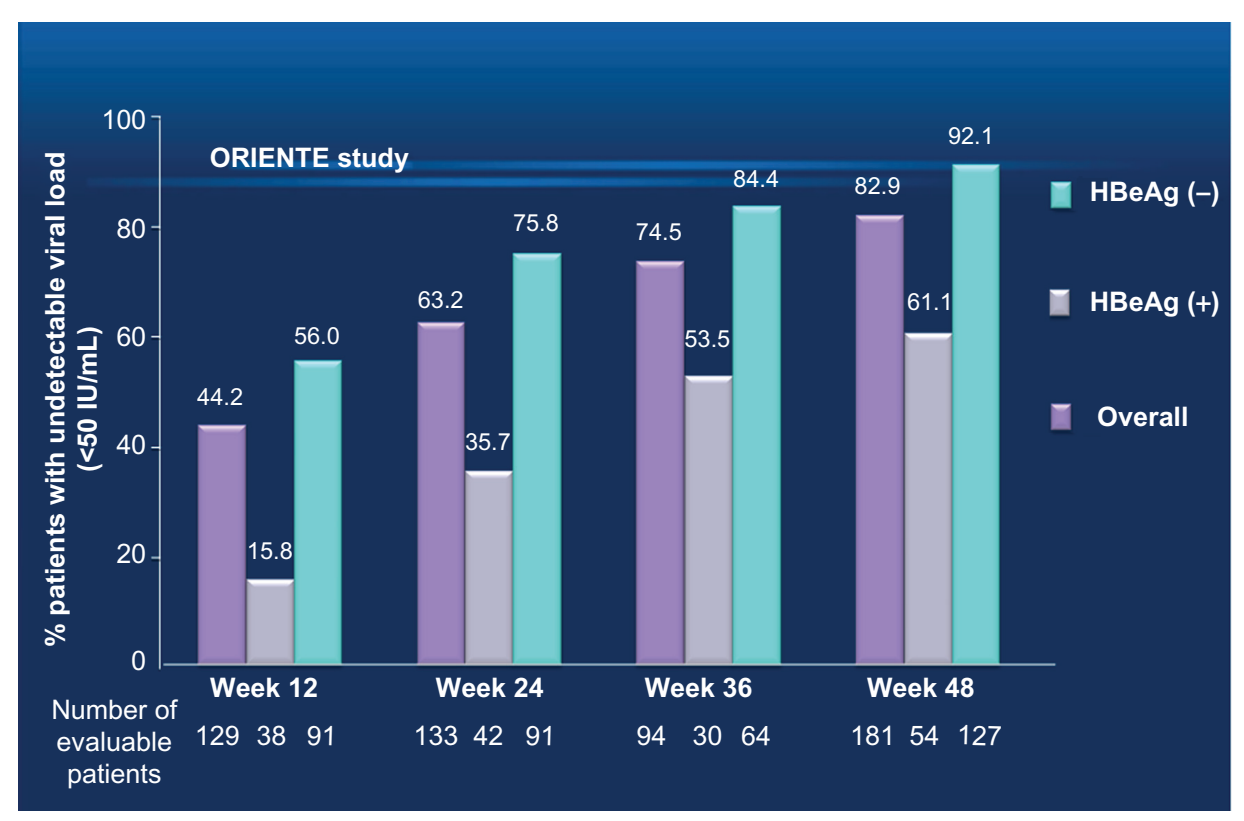

Figure 3 Proportion of HBsAg-positive and HBsAg-negative patients $(n=190)$ included in a Spanish database, who achieved undetectable viral load during 48-week treatment with entecavir.

Note: Data from Buti M, Morillas RM, Priet M, et al. A viral load reduction $>3$ log at 12 weeks of treatment with entecavir correlated with seroconversion to anti-HBe in HBeAg-positive patients. Results from a real-life setting study [The ORIENTE Study abstract 409]. Hepatology. 2010;52(Suppl I):523A-524A. ${ }^{38}$

Abbreviation: $\mathrm{HBsAg}$, hepatitis B surface antigen; $\mathrm{HBeAg}$, hepatitis B "e" antigen. 
developed resistance to entecavir. In total, 57 patients were experienced for antiviral treatment: a virological response was reached in $31(54 \%)$ patients over a median follow-up period of 12 months. Statistical analysis showed that patients with resistance to lamivudine at the initiation of entecavir treatment had a reduced probability of achieving a virological response, when compared with lamivudine-naïve patients (HR 0.14; 95\% CI 0.04-0.58; $P=0.007)$. However, the antiviral efficacy of entecavir was not decreased by prior treatment with lamivudine when lamivudine resistance had never developed (HR $0.81 ; 95 \%$ CI $0.43-1.52 ; P=0.52$ ). The response to entecavir was similar in patients previously treated with adefovir, regardless of the development of resistance to the latter drug. These findings were confirmed in a 144-week follow-up of this analysis, which was conducted on a larger number of patients $(\mathrm{n}=333) .{ }^{40}$ These results also showed that monotherapy with entecavir can be continued in patients naïve for nucleos(t)ide-analog treatment who still presented detectable HBV DNA at week 48, as the longterm continuation of entecavir therapy led to a virological response in the vast majority of patients. The prolonged therapy with entecavir was safe, even in the presence of cirrhosis, and had no impact on renal function.
Finally, the results of an Italian experience (conducted in 19 centers) have been recently reported in an abstract. ${ }^{41}$ In total, 418 consecutive treatment-naïve patients with chronic hepatitis B were treated with entecavir $(0.5 \mathrm{mg} /$ day $)$ for a period of 30 months. During entecavir treatment, a continuously increasing proportion of patients achieved undetectable HBV DNA or experienced normalization of alanine aminotransferase (Figure 4). Primary nonresponse at week 12, partial virological response at week 48 , and virological breakthroughs occurred in $<1 \%, 14 \%$, and $<1 \%$ of the patients, respectively, and no major safety issues were reported. The authors concluded that the vast majority of patients naïve for treatment with nucleos(t)ide analogs, who received monotherapy with entecavir, achieved and maintained a virological response over a 30-month period, even in a real-life clinical practice scenario.

\section{Implications for clinical practice and future research trends}

Entecavir is currently recommended as one of the preferred first-line agents for the treatment of HBV infection, due to its high genetic barrier. ${ }^{5}$ The efficacy and safety of this drug were assessed in a number of clinical trials and, as shown in the present review, mounting evidence supports therapy with

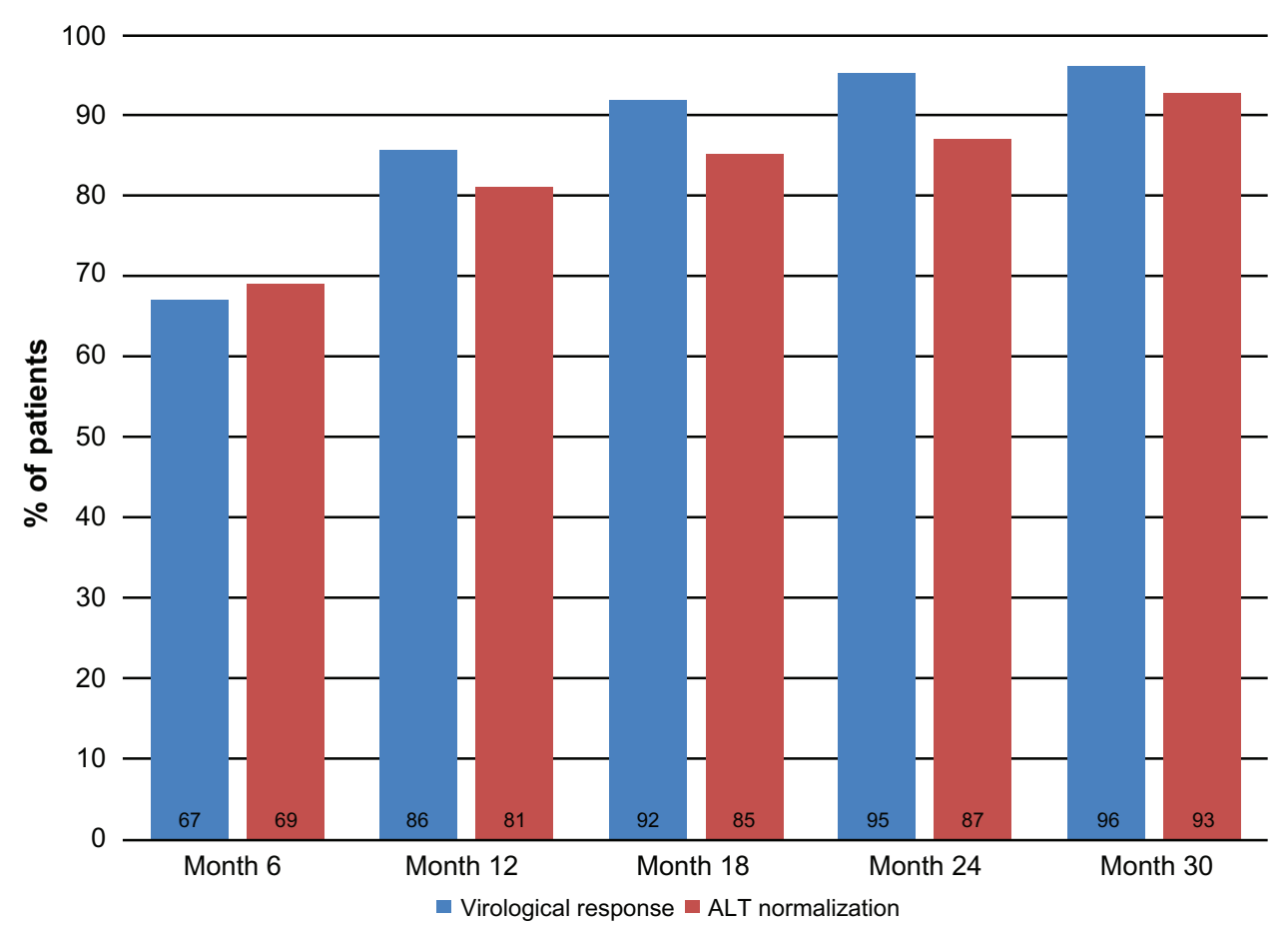

Figure 4 Proportion of nucleos $(t)$ ide-analog naïve patients included in an Italian database $(n=4 \mid 8)$, who achieved undetectable viral load or alanine aminotransferase $(A L T)$ normalization during 30-month treatment with entecavir.

Note: Data from Lampertico P, Vigano M, Soffredini R, et al. Maintained long-term suppression of HBV replication in NUC-naïve patients with chronic hepatitis B treated with ETV monotherapy in field practice. Poster 39I presented at the 6I th Annual Meeting of the American Association for the Study of Liver Diseases, Boston, MA, Hynes Convention Center October 30-November 3; 20I0. Available at: http://www.natap.org/20I0/AASLD/AASLD_70.htm. Accessed March 23, 20I2.41 
entecavir in patients with severe forms of hepatitis B, including those with decompensated cirrhosis, exacerbations of HBV infection, and fulminant hepatic failure. Entecavir may also be effective in patients who received a liver transplant or are immunocompromised - such as those affected by Crohn's disease - or, potentially, subjects undergoing immunosuppressive therapies. In addition, the wide use of entecavir in clinical practice has allowed for its robust evaluation in a real-life scenario.

Some new findings on entecavir treatment are emerging. Among these, the low incidence of HCC development appears to be of the highest relevance. Kobashi et al have described the results of a long-term (4.25 years), nonrandomized study in patients with either chronic hepatitis $B$ ( $n=194)$ or cirrhosis $(n=62)$, who were naïve for treatment with nucleos(t)ide analogs and treated with either entecavir or lamivudine. ${ }^{42}$ Over the follow-up period, 35 patients developed HCC (eleven in the entecavir group and 24 in the lamivudine arm); the difference between groups failed to achieve statistical significance. However, statistical analysis showed a significantly higher incidence of $\mathrm{HCC}$ in patients who developed resistance to lamivudine $(n=60)$, when compared with those without lamivudine resistance $(n=67$; $P=0.0352$ ). In our opinion, these interesting results deserve further evaluation given the high mortality rate associated with HCC.

Kobashi et al's findings received further support in a very recent study by Jin et al, which evaluated 231 nucleosidenaïve patients with chronic hepatitis $\mathrm{B}$, who were treated with entecavir; among these, 71 had HCC at the start of entecavir treatment. ${ }^{43}$ Patients with HCC showed similar cumulative rates of HBV-DNA negativization, alanine aminotransferase normalization, and hepatitis e antigen loss, when compared with those without HCC (100\% vs $95.4 \%$, 94.7\% vs $97.3 \%$, and $40.8 \%$ vs $41.8 \%$, respectively). The evaluation of the efficacy of entecavir in patients at risk for HCC, or patients who have already developed this severe condition, seems therefore a promising line of research. We advocate that further trials on the topic should be conducted in Western countries as well.

In our opinion, another interesting topic that deserves to be researched is the onset of lactic acidosis in patients treated with nucleos(t)ide analogs. In a small case series by Marzano et al on twelve HBV- or HCV-infected patients with decompensated cirrhosis and high Model for End-Stage Liver Disease scores, only one patient (out of six) with HBV infection developed lactic acidosis during entecavir treatment. ${ }^{44}$ Further trials are encouraged to confirm the lack of association between entecavir treatment and the onset of lactic acidosis in this population of patients.

\section{Conclusion}

On the basis of the evidence described, entecavir appears to be a suitable therapeutic strategy for the treatment of HBV infection, even in patients with the most severe forms of hepatitis. Additional research is ongoing to fully elucidate the effectiveness and safety of this drug in clinical practice.

\section{Disclosure}

The author declares no conflicts of interest in this work.

\section{References}

1. Lavanchy D. Worldwide epidemiology of HBV infection, disease burden, and vaccine prevention. J Clin Virol. 2005;34(Suppl 1):S1-S3.

2. Negro F. Management of chronic hepatitis B: an update. Swiss Med Wkly. 2011;141:w13264.

3. European Centre for Disease Prevention and Control. Hepatitis $B$ and $C$ in the EU Neighbourhood: Prevalence, Burden of Disease and Screening Policies. Technical report. Stockholm: European Centre for Disease Prevention and Control; 2010. Available from: http://www.ecdc. europa.eu/en/publications/Publications/TER_100914_Hep_B_C\%20_ EU_neighbourhood.pdf. Accessed September 24, 2011.

4. Nardone A, Anastassopoulou CG, Theeten H, et al. A comparison of hepatitis B seroepidemiology in ten European countries. Epidemiol Infect. 2009;137:961-969.

5. European Association for the Study of the Liver. EASL Clinical Practice Guidelines: management of chronic hepatitis B. J Hepatol. 2009;50(2):227-242.

6. Lok AS, McMahon BJ. Chronic hepatitis B: update 2009. Hepatology. 2009;50:661-662.

7. Hatzakis A, Wait S, Bruix J, et al. The state of hepatitis B and C in Europe: report from the Hepatitis B and C Summit Conference. JViral Hepat. 2011;18(Suppl 1):1-16.

8. Gonzalez SA, Keeffe EB. Entecavir for the long-term treatment of chronic hepatitis B. Expert Rev Anti Infect Ther. 2009;7(9):1053-1062.

9. Zoulim F. Hepatitis B virus resistance to antiviral drugs: where are we going? Liver Int. 2011;31(Suppl 1):111-116.

10. Dienstag JL. Hepatitis B virus infection. N Engl J Med. 2008;359(14): $1486-1500$.

11. Yamanaka G, Wilson T, Innaimo S, et al. Metabolic studies on BMS200475, a new antiviral compound active against hepatitis B virus. Antimicrob Agents Chemother. 1999;43(1):190-193.

12. Langley DR, Walsh AW, Baldick CJ, et al. Inhibition of hepatitis B virus polymerase by entecavir. J Virol. 2007;81(8):3992-4001.

13. Ono SK, Kato N, Shiratori Y, et al. The polymerase L528M mutation cooperates with nucleotide binding-site mutations, increasing hepatitis B virus replication and drug resistance. J Clin Invest. 2001; 107(4):449-455.

14. Levine S, Hernandez D, Yamanaka G, et al. Efficacies of entecavir against lamivudine resistant hepatitis B virus replication and recombinant polymerases in vitro. Antimicrob Agents Chemother. 2002; 46(8):2525-2532.

15. Wolters LM, Hansen BE, Niesters HG, DeHertogh D, de Man RA. Viral dynamics during and after entecavir therapy in patients with chronic hepatitis B. J Hepatol. 2002;37(1):137-144.

16. Leung N, Peng CY, Hann HW, et al. Early hepatitis B virus DNA reduction in hepatitis $\mathrm{B}$ e antigen-positive patients with chronic hepatitis B: A randomized international study of entecavir versus adefovir. Hepatology. 2009;49(1):72-79. 
17. Liaw YF, Sung JJ, Chow WC, et al; Cirrhosis Asian Lamivudine Multicentre Study Group. Lamivudine for patients with chronic hepatitis B and advanced liver disease. N Engl J Med. 2004;351(15): 1521-1531.

18. Lok AS, Lai CL, Leung N, Yao GB, et al. Long-term safety of lamivudine treatment in patients with chronic hepatitis B. Gastroenterology. 2003;125(6):1714-1722.

19. Ha NB, Ha NB, Garcia RT, et al. Renal dysfunction in chronic hepatitis B patients treated with adefovir dipivoxil. Hepatology. 2009; 50(3):727-734.

20. Hadziyannis SJ, Tassopoulos NC, Heathcote EJ, et al; Adefovir Dipivoxil 438 Study Group. Long-term therapy with adefovir dipivoxil for HBeAg-negative chronic hepatitis B for up to 5 years. Gastroenterology. 2006;131(6):1743-1751.

21. Liaw YF, Raptopoulou-Gigi M, Cheinquer H, et al. Efficacy and safety of entecavir versus adefovir in chronic hepatitis B patients with hepatic decompensation: a randomized, open label study. Hepatology. 2011; 54(1):91-100.

22. Liaw YF, Sheen IS, Lee CM, et al. Tenofovir disoproxil fumarate (TDF), emtricitabine/TDF, and entecavir in patients with decompensated chronic hepatitis B liver disease. Hepatology. 2011;53(1):62-72.

23. Seeff LB, Koff RS. Evolving concepts of the clinical and serologic consequences of hepatitis B virus infection. Semin Liver Dis. 1986;6: 11-22.

24. Perrillo RP. Acute flares in chronic hepatitis B: the natural and unnatural history of an immunologically mediated liver disease. Gastroenterology 2001;120:1009-1022.

25. Matsumoto K, Miyake Y, Miyatake H, et al. A combination treatment of entecavir and early-phase corticosteroid in severe exacerbation of chronic hepatitis B. World J Gastroenterol. 2009;15(13):1650-1652.

26. Wong VW, Wong GL, Yiu KK, et al. Entecavir treatment in patients with severe acute exacerbation of chronic hepatitis B. J Hepatol. 2011; 54(2):236-242.

27. Yamamoto T, Kondo S, Sugawara A, et al. Case of fulminant hepatic failure in an elderly asymptomatic HBV carrier without proximate cause. Nihon Shokakibyo Gakkai Zasshi. 2008;105(12):1781-1786. Japanese.

28. Wang YM, Tang YZ. Antiviral therapy for hepatitis B virus associated hepatic failure. Hepatobiliary Pancreat Dis Int. 2009;8(1):17-24.

29. Xi ZF, Xia Q, Zhang JJ, et al. The role of entecavir in preventing hepatitis B recurrence after liver transplantation. J Dig Dis. 2009;10(4): 321-327.

30. Kim WR, Poterucha JJ, Kremers WK, Ishitani MB, Dickson ER Outcome of liver transplantation for hepatitis B in the United States. Liver Transpl. 2004;10(8):968-974.

31. Olivera-Martínez MA, Gallegos-Orozco JF. Recurrent viral liver disease (hepatitis B and C) after liver transplantation. Arch Med Res. 2007;38(6):691-701.
32. Fung J, Cheung C, Chan SC, et al. Entecavir monotherapy is effective in suppressing hepatitis B virus after liver transplantation. Gastroenterology. 2011;141(4):1212-1219.

33. Brost S, Schnitzler P, Stremmel W, Eisenbach C. Entecavir as treatment for reactivation of hepatitis B in immunosuppressed patients. World $J$ Gastroenterol. 2010;16(43):5447-5451.

34. Sacco R, Bertini M, Bresci G, Romano A, Altomare E, Capria A. Entecavir for hepatitis B virus flare treatment in patients with Crohn's disease. Hepatogastroenterology. 2010;57(98):242-245.

35. Silverman SL. From randomized controlled trials to observational studies. Am J Med. 2009;122(2):114-120.

36. Wong VW, Sung JJ. Antiviral therapy for chronic hepatitis B: are we doing any good to patients? J Antimicrob Chemother. 2009;64(2): 223-226.

37. Marcellin P, Chousterman M, Fontanges T, et al; CheObs Study Group. Adherence to treatment and quality of life during hepatitis $\mathrm{C}$ therapy: a prospective, real-life, observational study. Liver Int. 2011;31(4): 516-524.

38. Buti M, Morillas RM, Priet M, et al. A viral load reduction $>3 \log$ at 12 weeks of entecavir treatment correlated with $\mathrm{HBe}$ seroconversion in $\mathrm{HBeAg}$-positive patients. Results from a real-life setting study [The ORIENTE Study]. Hepatology. 2010;52(Suppl 1):523A-524A.

39. Reijnders JG, Deterding K, Petersen J, et al. Antiviral effect of entecavir in chronic hepatitis B: influence of prior exposure to nucleos $(\mathrm{t})$ ide analogues. J Hepatol. 2010;52(4):493-500.

40. Zoutendijk R, Reijnders JG, Brown A, et al. Entecavir treatment for chronic hepatitis $\mathrm{B}$ : adaptation is not needed for the majority of naïve patients with a partial virological response. Hepatology. 2011; 54(2):443-451.

41. Lampertico P, Vigano M, Soffredini R, et al. Maintained long-term suppression of HBV replication in NUC-naïve patients with chronic hepatitis B treated with ETV monotherapy in field practice. Poster 391 presented at the 61th Annual Meeting of the American Association for the Study of Liver Diseases, Boston, MA, Hynes Convention Center October 30-November 3; 2010. Available at: http://www.natap. org/2010/AASLD/AASLD_70.htm. Accessed March 23, 2012.

42. Kobashi H, Miyake Y, Ikeda F, et al. Long-term outcome and hepatocellular carcinoma development in chronic hepatitis B or cirrhosis patients after nucleoside analog treatment with entecavir or lamivudine. Hepatol Res. 2011;41(5):405-416.

43. Jin YJ, Shim JH, Lee HC, et al. Suppressive effects of entecavir on hepatitis B virus and hepatocellular carcinoma. J Gastroenterol Hepatol. 2011;26(9):1380-1388.

44. Marzano A, Marengo A, Marietti M, Rizzetto M. Lactic acidosis during Entecavir treatment in decompensated hepatitis B virus-related cirrhosis. Dig Liver Dis. 2011;43(12):1027-1028.
Hepatic Medicine: Evidence and Research

\section{Publish your work in this journal}

Hepatic Medicine: Evidence and Research is an international, peerreviewed, open access journal covering all aspects of adult and pediatric hepatology in the clinic and laboratory including the following topics: Pathology, pathophysiology of hepatic disease; Investigation and treatment of hepatic disease; Pharmacology of drugs used for

\section{Dovepress}

the treatment of hepatic disease. Issues of patient safety and quality of care will also be considered. The manuscript management system is completely online and includes a very quick and fair peer-review system, which is all easy to use. Visit http://www.dovepress.com/ testimonials.php to read real quotes from published authors. 